\title{
Radiological findings in 31 patients with chondroblastoma in tubular and non-tubular bones
}

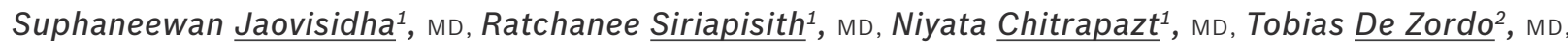 \\ Patarawan Woratanarat ${ }^{3}$,MD, PhD, Thanya Subhadrabandhu ${ }^{3}, \mathrm{MD}$, Vorachai Sirikulchayanonta ${ }^{4}, \mathrm{MD}$, \\ Pimjai Siriwongpairat ${ }^{1}$, MD
}

\begin{abstract}
INTRODUCTION This study aimed to evaluate radiological findings in patients with chondroblastoma (CB) in tubular and non-tubular bones (NTBs).

METHODS We retrospectively reviewed the medical records of patients with CB. Data collected included patients' gender and age, type, size and location of bone involved, and imaging findings regarding border, lobulation, calcification, trabeculation, cortical expansion and destruction, periosteal reaction, soft tissue component and fractures. Magnetic resonance imaging and/or multidetector computed tomography were used to determine the presence of any internal cystic space or secondary aneurysmal bone cyst that may have affected the radiological appearance of CB.

RESULTS All 31 lesions (18 tubular bones, 13 NTBs) exhibited geographic bone destruction and did not involve the adjacent joints. Univariate analysis showed that NTB lesions were found in older patients and were associated with thin trabeculation $(p<0.01)$ and well-defined margins $(p<0.05)$, whereas tubular bone lesions correlated with thick trabeculation and partially ill-defined margins. On multivariate analysis, age and type of bone involvement were significantly correlated. An increase in age by one year reduced the risk of having tubular bone involvement by about $27 \%$ when compared with NTBs $(p=0.011)$. Thin trabeculation was also significantly correlated with NTB lesions.

CONCLUSION Age was the most significant parameter, as increased age was found to reduce the risk of tubular bone involvement. Patients with NTB lesions were significantly older than those with tubular bone lesions. Based on imaging alone, thin trabeculation showed significant correlation with CB occurring in NTBs on both univariate and multivariate analyses.
\end{abstract}

Keywords: chondroblastoma, flat bone, non-tubular bone, radiograph, tubular bone

\section{INTRODUCTION}

Chondroblastoma (CB) is a rare, benign, cartilaginous lesion of the bones that accounts for less than $1 \%$ of primary bone tumours. ${ }^{(1,2)}$ It typically develops from the epiphysis of skeletally immature patients. ${ }^{(3,4)}$ Peak incidence of CB is seen in the second decade of life, ${ }^{(5,6)}$ and has been reported to occur more frequently in men than in women. ${ }^{(5,7-10)}$ Although $\mathrm{CB}$ has a predilection for tubular bones such as the humerus, femur, tibia and metatarsus, ${ }^{(7,11)}$ it can also be found in non-tubular bones (NTBs) such as flat bones (i.e. skull, maxilla and pelvis) ${ }^{(7)}$ and epiphysoid bones (i.e. trapezium, ${ }^{(12)}$ cuboid, $_{,}^{(13,14)}$ talus $^{(15,16)}$ and patella $\left.{ }^{(17)}\right)$. Multifocal benign CB has also been reported.(7) Radiological findings of $\mathrm{CB}$ include an osteolytic lesion located in the epiphysis or apophysis. A thin sclerotic rim and extension into subarticular bone or metaphysis is also well recognised, with metaphyseal involvement occurring in $25 \%-50 \%$ of patients. ${ }^{(8)}$ Calcific foci within the lesion have been reported in $30 \%-50 \%$ of patients, although the degree of calcification is variable. ${ }^{(8)}$ Radiological findings may remain nonspecific in patients when calcification is not visible or atypical features are encountered. ${ }^{(18)}$

Magnetic resonance (MR) imaging of $C B$ may help confirm radiographic diagnosis in certain patients. The features of $\mathrm{CB}$ on MR imaging include hypointense T2 signal in some portions of the lesions, ${ }^{(18-23)}$ adjacent bone marrow oedema and soft tissue oedema, periosteal reaction or periostitis, ${ }^{(18-24)}$ and fluid-fluid level. ${ }^{(25)}$ However, these MR imaging features have subsequently been reported in multiple types of osseous lesions ${ }^{(24,25)}$ other than $C B$, resulting in decreased specificity of $M R$ imaging for differential diagnosis of $\mathrm{CB}$. We observed that a substantial number of patients with CB in our hospital had lesions in NTBs. In 1973, McLeod and Beabout ${ }^{(26)}$ discussed the difficulties in diagnosing CB in NTBs at a time when MR imaging was not yet available as a diagnostic tool. Even in the present day, MR imaging and/or radiological findings in many instances do not allow for an unequivocal diagnosis of CB. Therefore, we undertook a study to determine whether the radiographic features of CB in NTBs were different from those in tubular bones. To the authors' knowledge, this is the first study investigating this aspect of $\mathrm{CB}$ in the English literature.

\section{METHODS}

This study was approved by the ethics committee at the Ramathibodi Hospital, Bangkok, Thailand (ID-10-52-01). We retrospectively reviewed the medical records of all patients with pathologically proven $\mathrm{CB}$ at our hospital during a 37-year period (1973-2009). A total of 31 patients (16 men; 15 women)

${ }^{1}$ Department of Radiology, Ramathibodi Hospital, Mahidol University, Bangkok, Thailand, ${ }^{2}$ Department of Radiology, Medical University Innsbruck, Innsbruck, Austria, ${ }^{3}$ Department of Orthopaedics, ${ }^{4}$ Department of Pathology, Ramathibodi Hospital, Mahidol University, Bangkok, Thailand

Correspondence: Dr Suphaneewan Jaovisidha, Professor, Department of Radiology, Ramathibodi Hospital, Rama 6 Street, Bangkok 10400, Thailand. rasjv@yahoo.com 

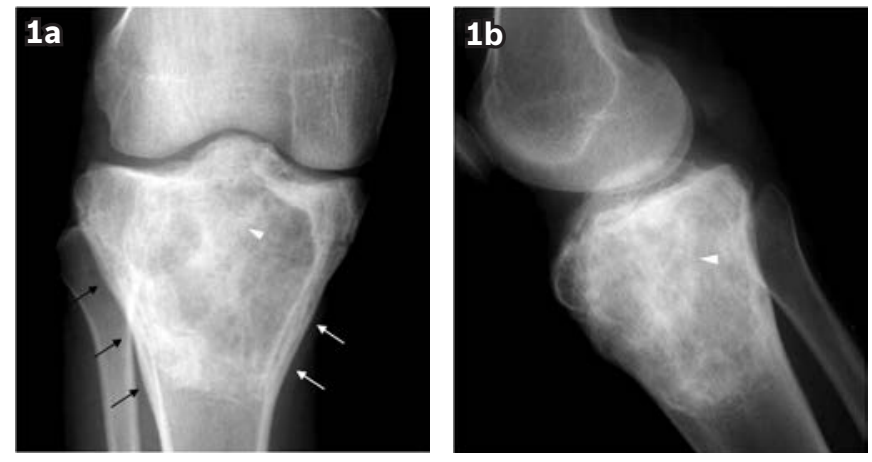

Fig. 1 Radiological findings in an 18 -year-old woman with chondroblastoma in the tubular bone (tibia). Plain radiographs of the knee in (a) anteroposterior and (b) lateral views show a partially ill-defined, lobulated, osteolytic lesion (with a partially sclerotic border) involving the proximal tibia, with extension to the subarticular bone superiorly. Slight expansion beyond the normal contour of bone is observed on the lateral (black arrows) and medial (white arrows) sides, with solid and lamellated periosteal reaction. Thick trabeculation is also detected (arrowheads).

who had radiographs at our institution were identified. The mean age of the patients was 18.9 (range 12-34) years. Conventional radiographic findings were evaluated by two radiologists and the features were recorded by consensus. Data collected included information on the bone involved, size, location, margin, transition zone, border, lobulation, calcification, trabeculation, cortical expansion, cortical destruction, periosteal reaction and soft tissue component, according to Lodwick et al's classification. ${ }^{(27)}$ Bones of origin were classified based on their gross appearances as either tubular bones (i.e. extremities and ribs) or NTBs, which included flat bones (such as the trunk, skull, scapula, sternum and pelvis) and epiphysoid bones (such as the patella, carpal and tarsal bones), in accordance with the guidelines of Dorfman and Czerniak. ${ }^{(28)}$

For 13 patients (6 men, 7 women; mean age 19 [range 11-34] years), additional MR imaging $(n=10)$ and multidetector computed tomography ( $\mathrm{CT} ; \mathrm{n}=2)$ studies were available, with both MR imaging and CT findings available for one patient. These imaging findings were evaluated for any visible internal cystic space (ICS), including cystic change and old bleeding, or secondary aneurysmal bone cyst (ABC), which may affect the radiological appearance of $\mathrm{CB}$. The sizes of the ICS and the entire tumour of each patient were recorded and the percentage values were calculated. The soft tissue component was evaluated using the best available imaging modality, with radiographs used if the results of CT/MR imaging investigations were unavailable.

For statistical analysis, continuous variables and categorical data were respectively presented as mean \pm standard deviation and percentage. To compare variables associated with $\mathrm{CB}$ in tubular bones and NTBs, univariate analysis was performed using unpaired $t$-test for continuous variables and Fisher's exact test for categorical variables. All variables identified as significant on univariate analysis underwent multivariate analysis in order to define the predictors associated with tubular bone involvement. All analyses were performed using STATA 10.0 (StataCorp,
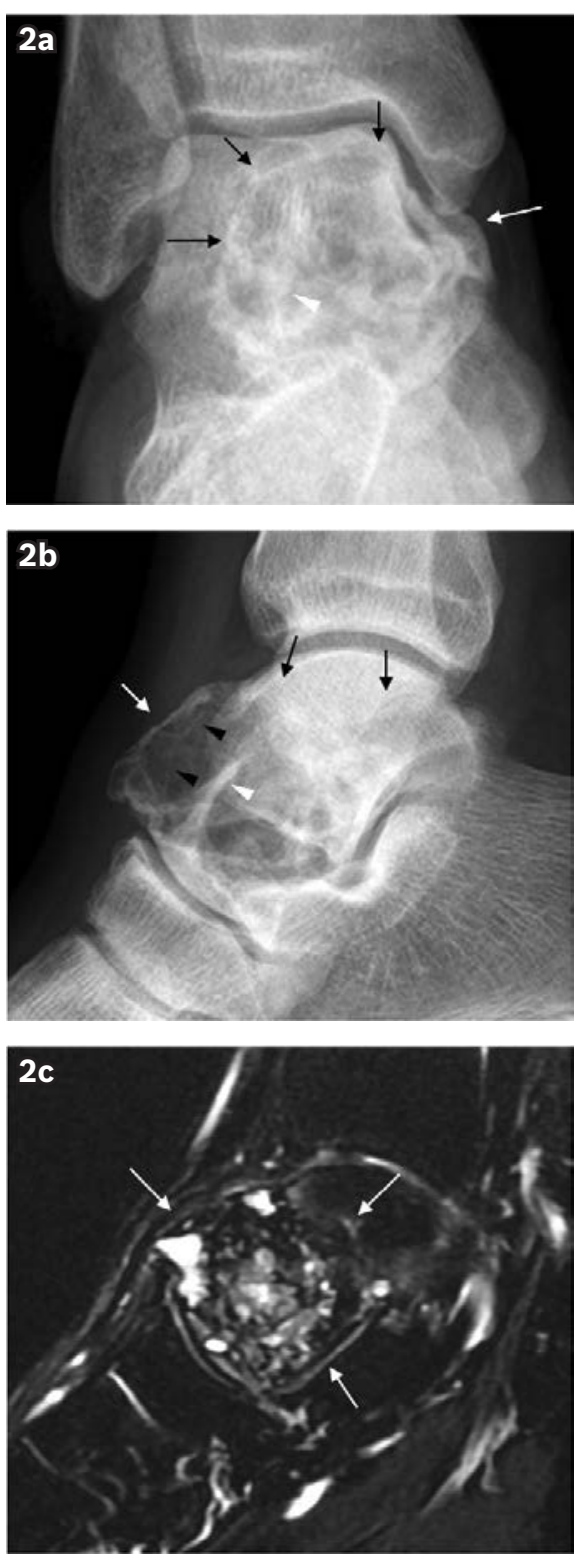

Fig. 2 Radiological findings in a 26 -year-old man with chondroblastoma in the non-tubular bone (talus). Plain radiographs of the ankle in (a) anteroposterior and (b) lateral views show a well-defined, lobulated, osteolytic expanding lesion (with a partially sclerotic border) involving almost the entire talus (black arrows indicate the border of the lesion). Note the thin (black arrowheads) and thick (white arrowheads) trabeculation. No periosteal reaction is seen even though there is expansion beyond the normal contour of the bone (white arrows). (c) Fatsuppressed T2-W MR imaging in sagittal plane (corresponding to the lateral radiograph) shows a lesion (white arrows) containing cystic change protruding anteriorly, with evidence of internal bleeding locules.

College Station, TX, USA). A p-value $<0.05$ was considered statistically significant.

\section{RESULTS}

A total of 18 lesions were found in tubular bones (femur, $\mathrm{n}=8$; tibia, $n=6$; humerus, $n=3$; fibula, $n=1$ ), and located in the epiphysis $(n=8)$, metaepiphysis $(n=8)$ and metaphysis $(n=2)$ (Fig. 1). A total of 13 lesions were seen in NTBs (talus, $n=7$; calcaneum, $\mathrm{n}=3$; patella, $\mathrm{n}=1$; sternum, $\mathrm{n}=1$; scapula, $\mathrm{n}=1$ ) (Fig. 2). On plain radiographs, all lesions showed geographic bone 
Table I. Univariate analysis of variables based on type of bone involvement in chondroblastoma.

\begin{tabular}{|c|c|c|c|c|c|c|c|}
\hline \multirow[t]{2}{*}{ Variable } & \multicolumn{2}{|c|}{ No. (\%) } & \multirow[t]{2}{*}{ p-value } & \multirow[t]{2}{*}{ Variable } & \multicolumn{2}{|c|}{ No. (\%) } & \multirow[t]{2}{*}{ p-value } \\
\hline & $\begin{array}{c}\text { Non-tubular } \\
\text { bone }(n=13)\end{array}$ & $\begin{array}{l}\text { Tubular bone } \\
(n=18)\end{array}$ & & & $\begin{array}{c}\text { Non-tubular } \\
\text { bone }(n=13)\end{array}$ & $\begin{array}{l}\text { Tubular bone } \\
\quad(n=18)\end{array}$ & \\
\hline Age* (yrs) $^{*}$ & $23.9 \pm 4.4$ & $16.4 \pm 5.5$ & $0.0005^{\ddagger}$ & Cortical expansion & & & \\
\hline Gender & & & & & $11(84.6)$ & $14(77.8)$ & 1.000 \\
\hline Female & $4(30.8)$ & $11(61.1)$ & 0.191 & 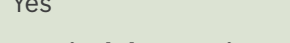 & & & \\
\hline Male & $8(61.5)$ & $7(38.9)$ & & Cortical destruction & & & \\
\hline Unknown ${ }^{\dagger}$ & $1(7.7)$ & 0 & & No & $10(76.9)$ & $10(55.6)$ & 0.275 \\
\hline Size* $\left.^{*} \mathrm{~cm}\right)$ & & & & Yes & $3(23.1)$ & $8(44.4)$ & \\
\hline Anteroposterior & $4.0 \pm 1.7$ & $3.8 \pm 1.5$ & $0.6891^{\S}$ & Periosteal reaction & & & \\
\hline Transverse & $3.8+1.9$ & $3.6+1.2$ & $0.6573^{\S}$ & & $13(100)$ & $13(72.2)$ & 0.058 \\
\hline Vertical & $\begin{array}{l}3.8 \pm 1.9 \\
3.5 \pm 2.1\end{array}$ & $\begin{array}{l}3.6 \pm 1.2 \\
4.7 \pm 2.2\end{array}$ & $0.65 / 3^{3}$ & Yes & 0 & $5(27.8)$ & \\
\hline Margin & & & & Type & & & \\
\hline Margin & & & & Solid & 0 & 0 & 0.120 \\
\hline Well-defined & $12(92.3)$ & $10(55.6)$ & $0.045^{\neq}$ & Lamellate & 0 & $4(22.2)$ & \\
\hline Partially ill-defined & $1(7.7)$ & $8(44.4)$ & & Codman & 0 & $1(5.6)$ & \\
\hline III-defined & 0 & 0 & & Sunray & 0 & 0 & \\
\hline Transition zone & & & & Soft tissue & & & \\
\hline Short & $12(92.3)$ & $17(94.4)$ & 1.000 & involvement ${ }^{\pi}$ & & & \\
\hline Wide & $1(7.7)$ & $1(5.6)$ & & No & $12(92.3)$ & $9(50.0)$ & $0.020^{\ddagger}$ \\
\hline Border & & & & Yes & $1(7.7)$ & $9(50.0)$ & \\
\hline No & $6(46.1)$ & 7 (38.9) & 0.724 & Eracture & & & \\
\hline Partial & 7 (53.9) & $9(50.0)$ & & Fracture & & & 70 \\
\hline Sclerotic & 0 & $2(11.1)$ & & $\begin{array}{l}\text { No } \\
\text { Yes }\end{array}$ & $\begin{array}{l}13(100) \\
0\end{array}$ & $\begin{array}{r}16(88.9) \\
2(11.1)\end{array}$ & 0.497 \\
\hline Lobulation & & & & & & & \\
\hline No & $9(69.2)$ & $13(72.2)$ & 1.000 & ICS/ABC on CT/ & & & \\
\hline Yes & $4(30.8)$ & $5(27.8)$ & & MR imaging & & & \\
\hline Calcification & & & & No & $\begin{array}{l}0 \\
3(231)\end{array}$ & $5(27.8)$ & 0.085 \\
\hline No & $6(46.1)$ & $6(33.3)$ & 0.710 & $\begin{array}{l}\text { Yes } \\
\text { No CT/MR imaging }\end{array}$ & $\begin{array}{r}3(23.1) \\
10(76.9)\end{array}$ & $\begin{array}{l}5(27.8) \\
8(44.4)\end{array}$ & \\
\hline Yes & 7 (53.9) & $12(66.7)$ & & 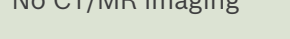 & & & \\
\hline Trabeculation & & & & ICS/ABC on histology & & & \\
\hline Ne & & & & No & $2(15.4)$ & $5(27.8)$ & 0.639 \\
\hline No & $1(7.7)$ & $4(22.2)$ & $0.004^{\ddagger}$ & Yes & $3(23.1)$ & $5(27.8)$ & \\
\hline Thin & $10(76.9)$ & $3(16.7)$ & & Not available & $8(66.5)$ & $8(44.4)$ & \\
\hline Thick & $2(15.4)$ & $11(61.1)$ & & for review & & & \\
\hline
\end{tabular}

${ }^{*}$ Data expressed as mean \pm standard deviation. ${ }^{\dagger}$ Not clear from old radiograph. ${ }^{\ddagger} p<0.05$ was statistically significant. ${ }^{\S}$ Unpaired $t$-test. ${ }^{\mathbb{9}}$ As determined by the best available modality.

ABC: aneurysmal bone cyst; CT: computed tomography; ICS: internal cystic space; MR: magnetic resonance

destruction and did not involve the adjacent joints. Table I shows the results of other variables.

On univariate analysis, lesions in NTBs were found in significantly older patients when compared to lesions in tubular bones (mean age, 23.9 years vs. 16.4 years; $p<0.001$ ). No gender-based differences with regard to incidence were found in our patients. CB with well-defined margins were detected in $92 \%$ of NTB lesions vs. $56 \%$ of tubular bone lesions, while partially ill-defined margins were present in $8 \%$ of NTB lesions vs. $44 \%$ of tubular bone lesions $(p<0.05)$. Short transition zones were observed in $>90 \%$ of all lesions ( $p=1.000)$. Lobulation was found in nearly $30 \%$ of lesions in both NTBs and tubular bones $(p=1.000)$. Calcification of CB was observed in approximately $54 \%$ of NTB lesions and $67 \%$ of tubular bone lesions $(p=0.710)$. Overall, trabeculation was present in about $84 \%$ of lesions. Thin trabeculation was found more often in NTB lesions (77\%) than in tubular bones $(17 \%)$, whereas thick trabeculation was more common in lesions in tubular bones $(61 \%)$ than in NTBs $(15 \%)(p<0.01)$. Trabeculation was absent in $8 \%$ of NTB lesions and $22 \%$ of lesions in tubular bone. Cortical destruction was more common in tubular bones $(44 \%)$ than in NTBs $(23 \%)(p=0.275)$. Periosteal reaction was found only in tubular bones ( $p=0.058)$. Soft tissue involvement was more frequently seen in tubular bones $(50 \%)$ than NTBs $(8 \%)$ $(p=0.020)$. Fractures $(n=2)$ were observed only in the tubular bones (humeri; 11\%).

On multivariate analysis, age was found to be significantly associated with type of bone involvement. An increase in age by one year reduced the risk of having tubular bone involvement by about $27 \%$ (adjusted odds ratio [OR] 0.73 , 95\% confidence interval $[\mathrm{Cl}]$ 0.58-0.93; $\mathrm{p}=0.011)$ when compared with NTB lesions (Table II). After age adjustment, the type of trabeculation did not show any significant relationship with the type of bone involvement. Based on radiological findings (without age adjustment), thin trabeculation was found to be significantly correlated with NTBs $(p=0.046)$ and thick trabeculation showed weak association with CB in tubular bones, although no statistical significance was found (Table III). Although on univariate analysis, soft tissue involvement showed significant correlation with $\mathrm{CB}$ in tubular bones, the association was not significant on multivariate analysis ( $p=0.185$; data not shown). With respect to the occurrence of ICS/ABC on CT/MR imaging and histological evaluations, there was no significant difference between lesions in NTBs and those in tubular bones (Table I). 
Table II. Results of multivariate analysis of parameters based on tubular bone involvement.

\begin{tabular}{lccc}
\hline Variable & $\begin{array}{c}\text { Adjusted OR } \\
(\mathbf{9 5 \%} \mathbf{~ C l})\end{array}$ & $\begin{array}{c}\text { Standard } \\
\text { error }\end{array}$ & p-value \\
\hline Age & $0.73(0.58-0.93)$ & 0.09 & $0.011^{\dagger}$ \\
Trabeculation* & & & \\
$\quad$ Thin & $0.12(0.04-3.41)$ & 0.21 & 0.217 \\
$\quad$ Thick & $4.67(0.12-168.9)$ & 8.55 & 0.400 \\
\hline
\end{tabular}

${ }^{*}$ Reference group - no trabeculation. ${ }^{\dagger} p<0.05$ was statistically significant.

$\mathrm{Cl}$ : confidence interval; OR: odds ratio

Table III. Results of multivariate analysis focused on radiological findings and tubular bone involvement.

\begin{tabular}{lccc}
\hline Trabeculation* & OR $(95 \% \mathrm{Cl})$ & $\begin{array}{c}\text { Standard } \\
\text { error }\end{array}$ & p-value \\
\hline Thin & $0.75(0.01-0.95)$ & 0.10 & $0.046^{\dagger}$ \\
Thick & $1.37(0.10-19.64)$ & 1.87 & 0.814 \\
\hline
\end{tabular}

${ }^{\star}$ Reference group - no trabeculation. ${ }^{\dagger} p<0.05$ was statistically significant.

$\mathrm{Cl}$ : confidence interval; OR: odds ratio

Table IV. Correlation between the imaging size of chondroblastoma and internal cystic space/aneurysmal bone cyst.

\begin{tabular}{lrrr}
\hline Size & $\begin{array}{c}\text { Correlation coefficient } \\
(\mathbf{9 5 \%} \mathbf{~ C l})\end{array}$ & $\begin{array}{c}\text { Standard } \\
\text { error }\end{array}$ & p-value \\
\hline Anteroposterior & $10.25(-16.90$ to 37.47$)$ & 11.12 & 0.392 \\
Transverse & $10.17(-13.58$ to 33.91) & 9.70 & 0.335 \\
Vertical & $6.49(-10.08$ to 23.05$)$ & 6.77 & 0.375 \\
\hline
\end{tabular}

$\mathrm{Cl}$ : confidence interval

Analysis of correlation between the radiological size of the tumour (in the anteroposterior, transverse and vertical dimensions) and the size of ICS/ABC on CT/MR imaging showed correlation coefficients of $10.25,10.17$, and 6.49 , respectively. This implied a correlation between increasing ICS/ABC size on CT/MR imaging and increasing radiological size of tumour in each dimension, although this association was not found to be statistically significant (Table IV). No correlations were found between ICS/ABC on CT/MR imaging and trabeculation $(p=0.755 ;$ Table $\mathrm{V}), \mathrm{ICS} / \mathrm{ABC}$ on histology and trabeculation $(p=0.413$; Table $\mathrm{VI})$, or ICS/ABC on histology and ICS/ABC on CT/MR imaging $(p=0.190 ;$ Table VI). However, the presence of ICS/ABC on histology was associated with an increased risk of ICS/ABC, detected on CT/MR imaging (OR 15.0, 95\% CI 0.66-339.55; $p=0.089 ;$ Table VII).

\section{DISCUSSION}

We found that the incidence of NTB involvement in patients with $\mathrm{CB}$ was significantly higher in older patients (mean age 24 years) than in patients with tubular bone involvement (mean age 16 years). This finding is in agreement with Bloem and Mulder's study of 104 patients with CB, which reported that patients with tumours located in flat or short tubular bones were older (mean age 28 years) than those with tumours in the long bones (mean age 16 years). ${ }^{(29)}$ Similar observations were made by Ramappa et al, ${ }^{(30)}$ although the authors did not investigate this aspect in detail. Multivariate analysis in our study also
Table V. Relationship between internal cystic space (ICS)/ aneurysmal bone cyst (ABC) on CT/MR imaging and trabeculation.

\begin{tabular}{llcl}
\hline Trabeculation & \multicolumn{2}{c}{$\begin{array}{c}\text { No. of cases with ICS/ABC } \\
\text { on CT/MR imaging (\%) }\end{array}$} & p-value* \\
\cline { 2 - 3 } & No & Yes & \\
\hline No & $2(40.0)$ & $1(12.5)$ & 0.755 \\
Thin & $1(20.0)$ & $2(25.0)$ & \\
Thick & $2(40.0)$ & $5(62.5)$ & \\
\hline
\end{tabular}

${ }^{*}$ Fisher exact test. CT: computed tomography; MR: magnetic resonance

Table VI. Factors related to internal cystic space (ICS)/ aneurysmal bone cyst $(A B C)$ on histology.

\begin{tabular}{lccc}
\hline Variable & \multicolumn{2}{c}{$\begin{array}{c}\text { o. of cases with ICS/ABC } \\
\text { on histology (\%) }\end{array}$} & p-value* \\
\cline { 2 - 3 } & No & Yes & \\
\cline { 2 - 3 } Trabeculation & & & \multirow{2}{*}{0.413} \\
$\quad$ No & $2(28.6)$ & $1(12.5)$ & \\
Thin & $1(14.3)$ & $4(50.0)$ & \\
Thick & $4(57.1)$ & $3(37.5)$ & \\
ICS/ABC on & & & 0.190 \\
CT/MR imaging & & & \\
$\quad$ No & $3(75.0)$ & $1(16.7)$ & \\
Yes & $1(25.0)$ & $5(83.3)$ & \\
\end{tabular}

${ }^{*}$ Fisher exact test. CT: computed tomography; MR: magnetic resonance

Table VII. Odds ratio of internal cystic space (ICS)/aneurysmal bone cyst $(A B C)$ on histology.

\begin{tabular}{lccc}
\hline $\begin{array}{l}\text { ICS/ABC on CT/ } \\
\text { MR imaging }\end{array}$ & OR $(95 \% \mathrm{CI})$ & $\begin{array}{c}\text { Standard } \\
\text { error }\end{array}$ & p-value \\
\hline No & & & \\
Yes & $15.0(0.66-339.55)$ & 23.87 & 0.089 \\
\hline
\end{tabular}

$\mathrm{Cl}$ : confidence interval; $\mathrm{CT}$ : computed tomography; MR: magnetic resonance; OR: odds ratio

revealed that age was significantly associated with the type of bone involvement. An increase in age by one year was found to be associated with a reduced risk of tubular bone involvement by nearly $27 \%$ compared to lesions in NTBs. It is likely that this finding is related to the closure of the epiphyseal plate with increasing age.

In our study, the key radiological difference between CB lesions in NTBs and those in tubular bones was that thin trabeculation was more commonly found in NTBs than in tubular bones. Also, there was significant association between thin trabeculation and NTB involvement on both univariate and multivariate analyses. Reported to be rare in cases of CB, Lodwick et $\mathrm{al}^{(27)}$ has previously suggested that trabeculation was an atypical feature in the diagnosis of CB. Nevertheless, Bloem and Mulder observed a higher incidence of trabeculation in flat bones (67\%) than in long bones (53\%). ${ }^{(29)}$ Our results, although not identical to Bloem and Mulder's, likewise revealed a higher incidence of trabeculation in CB lesions of NTBs and tubular bones. Overall, trabeculation was found in $84 \%$ of lesions, affecting $92 \%$ and $78 \%$ of lesions in NTBs and tubular bones, respectively. In our cohort of patients, NTB lesions were significantly associated with thin trabeculation $(77 \%)$, whereas 
tubular bone lesions appeared to have a greater association with thick trabeculation (61\%). To the authors' knowledge, this is the first study that describes such an association.

Aronsohn et $\mathrm{al}^{(10)}$ found that $92 \%$ of $\mathrm{CB}$ lesions had distinct, well-defined margins throughout. The only lesion found to have a poorly defined margin was likely related to its large size $(14 \mathrm{~cm}) .{ }^{(10)}$ In our study, we found well-defined margins in $71 \%$ of the lesions (22/31). NTB lesions were associated with welldefined margins (92\%) in our patients. Tubular bone lesions, however, showed a higher frequency of partially ill-defined margins (44\%) than NTB lesions (8\%). These findings, which were statistically significant, concur with Bloem and Mulder's findings that a majority of tumours had sharp margins, and that ill-defined margins were detected in some parts in $26 \%$ of long bone lesions. ${ }^{(29)}$

In our study, periosteal reaction was found in $5(16 \%)$ tubular bone lesions, with lamellated periosteal reaction being the most common (4/5). McLeod and Beabout, ${ }^{(26)}$ and Aronsohn et al ${ }^{(10)}$ reported that $10 \%$ of $\mathrm{CB}$ lesions exhibited dense periosteal reaction and coarse parallel lamination. Studying radiographic periostitis in $\mathrm{CB}$, Brower et al reported a thick, solid or layered periosteal response in $53 \%$ of lesions in long bones, and in $15 \%$ of lesions located in other parts of the skeleton. ${ }^{(22)}$ Our results also suggest that periosteal reaction has a greater association with $\mathrm{CB}$ in long bones than with CB in other types of bone $(p=0.058)$. Soft tissue involvement in our patients, which was evaluated from the best available imaging modality, was more frequently found in lesions of tubular bones than in NTBs, although this was not statistically significant on multivariate analysis. Other studies have suggested that periosteal reaction and soft tissue involvement (mainly soft tissue oedema), when present, are more easily detected by MR imaging than plain radiographs, and that they are the result of inflammatory reaction. ${ }^{(18,19,21,23)}$ However, these reports did not mention any differences in periosteal reaction and soft tissue involvement between long bones and other types of bone.

The talus (7/13) was the most commonly involved NTB in our study, possibly because the origination of benign, cartilageforming tumours is usually closely related to the growth of cartilage. ${ }^{(31,32)}$ The talus is a bone uniquely different from others, as it grows by enchondral ossification within cartilage anlagen. ${ }^{(33)}$ When ossification of the cartilage anlagen is complete, two-thirds of the talar surface would be covered by articular cartilage. ${ }^{(34,35)}$ This may thus entail a higher likelihood of developing cartilage tumour in the talus than in other bones. While McLeod and Beabout found cortical expansion in more than half of the 72 lesions in their study, ${ }^{(26)}$ our results suggest that cortical expansion in NTBs $(15 \%)$ was less common than in tubular bones $(22 \%)$. Our findings are also contrary to those of Bloem and Mulder, who reported cortical expansion in $63 \%$ and $31 \%$ of flat and long bone lesions, respectively. ${ }^{(29)}$ Similarly, although McLeod and Beabout reported areas of local cortical destruction in only 5 (7\%) lesions in their study, ${ }^{(26)}$ we found 11 out of 31 (35\%) lesions with local cortical destruction among our patients, similar to the finding of $30 \%$ by Bloem and Mulder. ${ }^{(29)}$ We also found that of the 11 lesions with local cortical destruction, only six had cortical expansion, suggesting that $\mathrm{CB}$ may be associated with cortical destruction not preceded by cortical expansion.

Secondary $A B C$, considered a complication that can cause marked expansion and blowout features in $\mathrm{CB}$, is seen pathologically in about $15 \%-20 \%$ of patients and is most common in the tarsal bones. ${ }^{(36)}$ On imaging studies, particularly $C T$ and MR imaging, it is difficult to differentiate between ICS and $A B C$, as blood may appear as simple fluid after haemolysis. ICS and $A B C$ were therefore recorded as a single entity in our study. We found that the increasing radiological size of $C B$ in each dimension was related to the increasing size of ICS/ABC detected on CT/MR imaging, although the association was not statistically significant. No correlations were found between ICS/ABC on CT/MR imaging and trabeculation, ICS/ABC on histology and trabeculation, and ICS/ABC on histology and ICS/ $\mathrm{ABC}$ on $\mathrm{CT} / \mathrm{MR}$ imaging. Nonetheless, the presence of ICS/ABC on histology appeared to be linked with an increased likelihood of detecting ICS/ABC on CT/MR imaging.

There are some limitations in this study. First, the statistical power of the study is limited by its small sample size. Second, as a retrospective study spanning 37 years, the data collected were not comprehensive and complete for all enrolled patients, as only plain radiographs were available for the earlier patients at the time of analysis. This shortcoming could limit the validity of our analysis in certain aspects, such as the presence of ICS or soft tissue involvement. Third, as three-dimensional imaging was not routinely performed, the sizes of the tumour and ICS in our patients were calculated based on two-dimensional measurements instead of volume. Therefore, it is possible that these results may not be as accurate or representative of the actual size of the lesions.

In summary, we found that CB in NTBs occurred in patients who were significantly older than those with lesions in tubular bones. We also found that an increase of one year in age reduces the risk of tubular bone involvement by nearly $27 \%$ compared to NTBs. On imaging alone, CB in NTBs was significantly correlated with thin trabeculation, whereas lesions in tubular bones appeared to be associated with thick trabeculation. To our knowledge, no previous study in the literature has described such associations. NTB lesions were also more likely than tubular bones lesions to have well-defined margins without periosteal reaction.

\section{ACKNOWLEDGEMENT}

The authors thank Dr Amnuay Thithapandha for his assistance in the editing of this manuscript.

\section{REFERENCES}

1. Papaioannou G, Sebire NJ, McHugh K. Imaging of the unusual pediatric "blastomas". Cancer Imaging 2009; 9:1-11.

2. Davila JA, Amrami KK, Sundaram M, Adkins MC, Unni KK. Chondroblastoma of the hands and feet. Skeletal Radiol 2004; 33:582-7. 
3. Azouz EM. Magnetic resonance imaging of benign bone lesions: cysts and tumors. Top Magn Reson Imaging 2002; 13:219-29.

4. Garin IE, Wang EH. Chondroblastoma. J Orthop Surg (Hong Kong) 2008; 16:84-7.

5. Springfield DS, Capanna R, Gherlinzoni F, Picci P, Campanacci M. Chondroblastoma: A review of seventy cases. J Bone Joint Surg Am 1985; 67:748-55.

6. Lester EW. Neoplastic, metabolic, and inflammatory disorders of the bones and joints. In: Stocker JT, Louis PD, eds. Pediatric Pathology. Philadelphia: JB Lippincott, 1992: 1224-5.

7. Tachdjian MO. Bone: Benign chondroblastoma. In: Tachdjian MO, ed. Pediatric Orthopedics. 2nd ed. Philadelphia: WB Saunder, 1990: 1200-3.

8. Resnick D. Tumor and tumor-like lesions of bone. In: Resnick D, ed. Diagnostic of Bone and Joint Disorders. 4th Ed. Philadelphia: WB Saunder, 2002: 3850-66.

9. Schajowicz F, Gallardo H. Epiphysial chondroblastoma of bone. A clinicopathological study of sixty-nine cases. J Bone Joint Surg Br 1970; 52:205-26.

10. Aronsohn RS, Hart WR, Martel W. Metaphyseal chondroblastoma of bone. AJR Am J Roentgenol 1976; 127:686-8.

11. Jarkiewicz-Kochman E, Golebiowski M, Swiatkowski J, Pacholec E, Rajewski R. Tumors of the metatarsus. Ortop Traumatol Rehabil 2007; 9:319-30.

12. Konishi $\mathrm{E}$, Okubo $\mathrm{T}$, Itoi $\mathrm{M}$, et al. Chondroblastoma of trapezium with metacarpal involvement. Healio Orthopedics 2008; 31. Available at: http:// www.OrthoSuperSite.com/view.asp?rID=27103. Accessed May 30, 2011.

13. Sessions W, Siegel HJ, Thomas J, et al. Chondroblastoma with associated aneurysmal bone cyst of the cuboid. J Foot Ankle Surg 2005; 44:64-7.

14. Sepah YJ, Umer M, Minhas K, Hafeez K. Chondroblastoma of the cuboid with an associated aneurismal bone cyst: a case report. J Med Case Rep 2007; 1:135. Available at: http://www.jmedicalcase reports.com/ content/1/1/135. Accessed May 31, 2011.

15. Breck LW, Emmett JE. Chondroblastoma of the talus: a case report. Clin Orthop 1956; 7:132-5.

16. Moore TM, Roe JB, Harvey JP Jr. Chondroblastoma of the talus: a case report. J Bone Joint Surg Am 1977; 59:830-1.

17. Trebse R, Rotter A, Pisot V. Chondroblastoma of the patella associated with an aneurysmal bone cyst. Acta Orthop Belg 2001; 67:290-6.

18. Weatherall PT, Maale GE, Mendelsohn DB, et al. Chondroblastoma: classic and confusing appearance at MR imaging. Radiology 1994; 190:467-74.

19. Oxtoby JW, Davies AM. MRI characteristics of chondroblastoma. Clin Radiol 1996; 51:22-6.
20. Jee WH, Park YK, McCauley TR, et al. Chondroblastoma: MR characteristics with pathologic correlation. J Comput Assist Tomogr 1999; 23:721-6.

21. Yamamura S, Sato K, Sugiura H, Iwata H. Inflammatory reaction in chondroblastoma. Skeletal Radiol 1996; 25:371-6.

22. Brower AC, Moser RP, Kransdorf MJ. The frequency and diagnostic significance of periostitis in chondroblastoma. AJR Am J Roentgenol 1990; 154:309-14.

23. Hayes CW, Conway WF, Sundaram M. Misleading aggressive MR imaging appearance of some benign musculoskeletal lesions. RadioGraphics $1992 ; 12: 1119-34$

24. James SL, Panicek DM, Davies AM. Bone marrow oedema associated with benign and malignant bone tumours. Eur J Radiol 2008; 67:11-21.

25. Keenan S, Bui-Mansfield LT. Musculoskeletal lesions with fluid-fluid level: a pictorial essay. J Comput Assist Tomogr 2006; 30:517-24.

26. McLeod RA, Beabout JW. The roentgenographic features of chondroblastoma. Am J Roentgenol Radium Ther Nucl Med 1973 118:464-71.

27. Lodwick GS, Wilson AJ, Farrell C, Virtama P, Dittrich F. Determining growth rates of focal lesions of bone from radiographs. Radiology 1980; 134:577-83.

28. Dorfman HD, Czerniak B. General consideration. In: Dorfman HD, Czerniak B, eds. Bone Tumors. St Louis: Mosby, 1998: 1-7.

29. Bloem JL, Mulder JD. Chondrobalstoma: A clinical and radiological study of 104 cases. Skeletal Radiol 1985; 14:1-9.

30. Ramappa AJ, Lee FY, Tang P, et al. Chondroblastoma of bone. J Bone Joint Surg Am 2000; 82:1140-5.

31. Schajowicz F. Chondroblastoma. In: Schajowicz F ed. Tumors and Tumorlike Lesions of Bone: Pathology, Radiology and Treatment. Berlin: Springer Verlag, 1994: 173-89.

32. D'Ambrosia R, Ferguson AB Jr. The formation of osteochondroma by epiphyseal cartilage transplantation. Clin Orthop Relat Res 1968; 61:103-15.

33. Larocca H. Embryology of the neuromusculoskeletal apparatus. In: Lowell WW, Winter RB, eds. Pediatric Orthopaedic. Philadelphia: JB Lippincott, 1986: 1-39.

34. Sarrafian SK. Anatomy of the foot and ankle. Philadelphia: JB Lippincott 1983: 47-54.

35. Kleiger B. Injuries of the talus and its joints. Clin Orthop Relat Res 1976; 121:243-62.

36. Dorfman HD, Czerniak B. Benign cartilage lesions. In: Dorfman HD, Czerniak B, eds. Bone Tumors. St Louis: Mosby, 1998: 296-321.

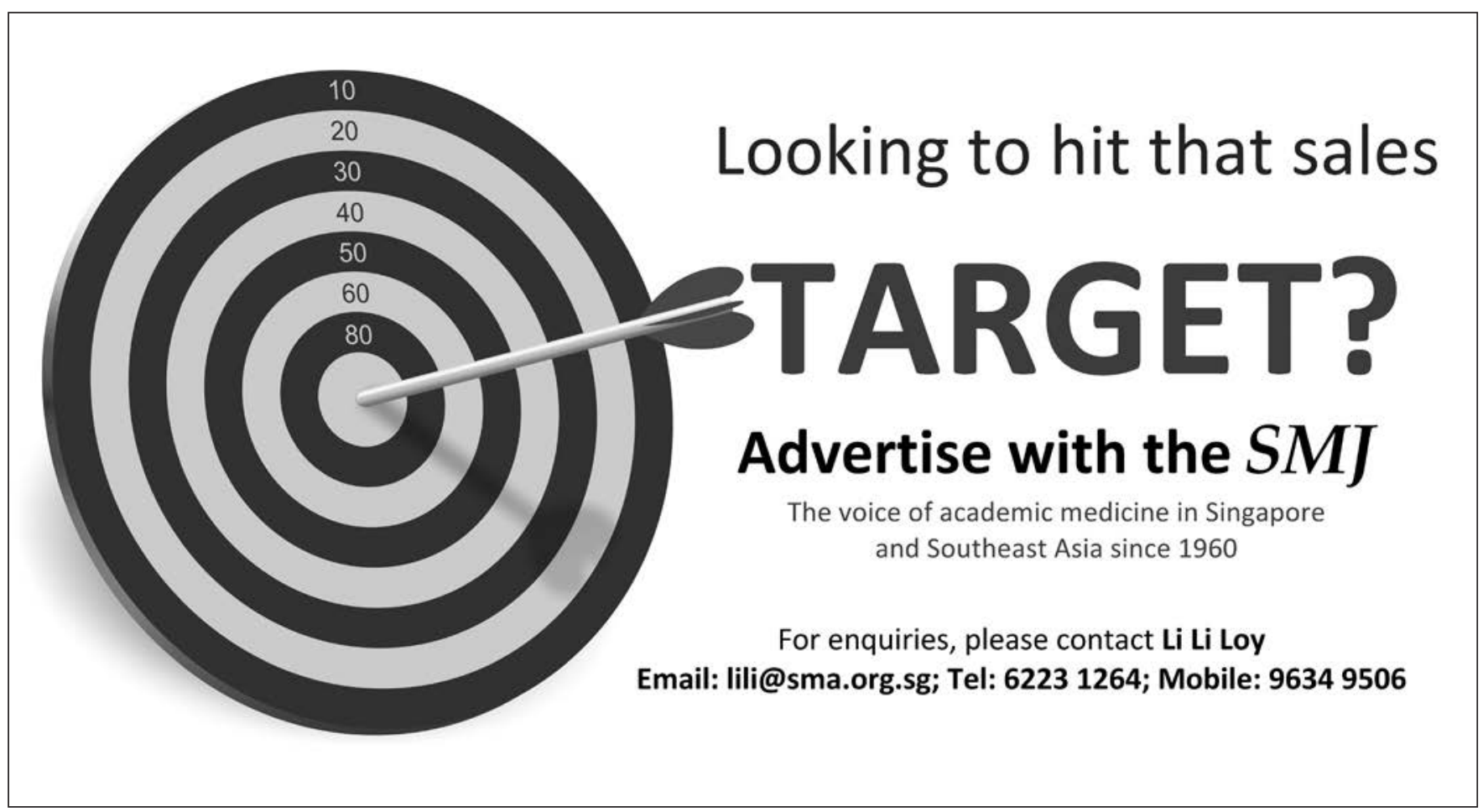

